\title{
Development of a Web-Based Musculoskeletal Pain Management Information System
}

\author{
${ }^{1}$ Oluwole B. Olajide, ${ }^{2}$ Ikechukwu Nwosu and ${ }^{3}$ Samson Oluyemi Sogunro \\ ${ }^{1}$ College of Physical \& Applied Sciences, McPherson University, Ajebo, Ogun State, Nigeria; \\ ${ }^{2}$ Faculty of Arts, Computing, Engineering and Social Sciences, Sheffield Hallam University; Sheffield, UK; \\ ob.olajide@gmail.com; ronsynwosu@gmail.com; samson.sogunro@gmail.com
}

\begin{abstract}
Musculoskeletal symptoms among adolescents are related to the time spent using a computer, but little is known about the seriousness of the symptoms or how much they affect everyday life. The purpose of the present study was to examine the intensity of musculoskeletal pain and level of inconvenience to everyday life, in relation to time spent using a computer. This paper developed a system that determines the likelihood of musculoskeletal pain and uses the data stored from the likelihood in developing a predictive model to re-evaluate future data; achieved by - identifying the risk factors and their relationship with the likelihood of musculoskeletal pain, design the system which will be used in the development and implement the design using java programming language.

The methodology of the system involved the identification of the requirements and their relationship with the determination of musculoskeletal pain likelihood; the model involved the allocation of points to each label of the risk factors. Ranges of the sum of points are then used to determine the musculoskeletal pain of each user. The input risk factors' data were collected from a number of participants as patients which were processed in determining their respective status (unlikely, likely, benign and malignant)-the data was later converted into an .arff file format. For the implementation, the software used in performing the detection was implemented in java using the Netbeans IDE 7.1 while the predictive models were implemented using the java API,- a java oriented; data mining tool used for performing classification and forecasting. At baseline a self-administered questionnaire was distributed to 853 participants from 46 different work sites (382 men and 471 women) who, at baseline, had been free from neck and upper extremity symptoms during the preceding month. Work-related exposures, individual factors, and symptoms from the neck and upper extremities were assessed.
\end{abstract}

Observations of working technique were performed by ergonomists using an ergonomic checklist. Incidence data were collected asking for information on the occurrence of neck, shoulder and arm/hand symptoms. Perceived exertion was rated on a modified scale ranging from 0 (very, very light) to 14 (very, very strenuous). Perceived comfort was rated on a 9-point scale ranging from -4 (very, very poor) to +4 (very, very good) in relation to the chair, computer screen, keyboard, and computer mouse. It was also observed that correct alignment with the computer reduces all the musculoskeletal pain and thus corrects the computer users about the use of ergonomic sitting posture when using the computer. There was a strong association between high perceived exertion and the development of neck, shoulder, and

DOI: $10.14738 /$ tnc.36.1569

Publication Date: $10^{\text {th }}$ November 2015

URL: http://dx.doi.org/10.14738/tnc.36.1569 
Oluwole B. Olajide, Ikechukwu Nwosu and Samson Oluyemi Sogunro; Development of a Web-Based Musculoskeletal Pain Management Information System, Transactions on Networks and Communications,

Volume 3 No. 6, December (2015); pp: 1-17

arm/hand symptoms. Moreover, there was an association between poor perceived comfort and neck pain. Surveillance of computer users may include perceived exertion and comfort to target individuals at risk for neck and upper extremity symptoms.

Keywords: Musculoskeletal Pain; Management Information System; Web Based Development.

\section{Introduction}

As a body of knowledge, human-factors engineering is a collection of data and principles about human characteristics, capabilities, and limitations in relation to machines, jobs, and environments [1]. As a process, it refers to the design of machines, machine systems, work methods, and environments to take into account the safety, comfort, and productiveness of human users and operators [15]. As a profession, human-factors engineering includes a range of scientists and engineers from several disciplines that are concerned with individuals and small groups at work [5].

The terms human-factors engineering and human engineering are used interchangeably on the North American continent. In Europe, Japan, and most of the rest of the world the prevalent term is ergonomics, a word made up of the Greek words, ergon, meaning "work," and nomos, meaning "law" [42]. Despite minor differences in emphasis, the terms human-factors engineering and ergonomics may be considered synonymous.

Human factors and human engineering were used in the 1920 s and '30s to refer to problems of human relations in industry, an older connotation that has gradually dropped out of use [4]. Some small specialized groups prefer such labels as bioastronautics, biodynamic, bioengineering, and mannedsystems technology; these represent special emphases whose differences are much smaller than the similarities in their aims and goals.

The data and principles of human-factors engineering are concerned with human performance, behavior, and training in man-machine systems; the design and development of man-machine systems; and systems-related biological or medical research. Because of its broad scope, human-factors engineering draws upon parts of such social or physiological sciences as anatomy, anthropometry, applied physiology, environmental medicine, psychology, sociology, and toxicology, as well as parts of engineering, industrial design, and operations research [16].

Musculoskeletal pains and aches are prevalent in the general population in many countries. Within the European Union (EU) a 12 month prevalence of $23 \%$ has been reported for work related musculoskeletal disorders [15]. In Sweden the prevalence of these disorders has decreased slightly during recent years but it still constitutes one of the major risk factors leading to long term sick leave.

Apart from individual suffering and a decrease in the quality of life, these disorders place a heavy economic burden on society due to costs connected to long term sick leave, poorer work performance and reduced productivity [27]. The causes of work related neck and upper extremity symptoms continue to be insufficiently understood. Both cross sectional and longitudinal studies have suggested, however, that factors related to the individual (e.g. age and gender), working technique, working postures, muscular rest and perceived muscle tension as well as factors related to the work place or work organization, such as workplace layout, repetitive and constrained work and psychosocial working conditions, may be potential risk factors [13]. 
Similar risk factors have been found for computer work. For instance, poor working technique or work style, as described by [13] has been shown to be associated with an increased risk of developing symptoms indicative of neck and upper extremity disorders. Over the years, several models have been developed in an attempt to identify and explain possible links between different exposures, early signs of incipient musculoskeletal pain conditions and more manifest musculoskeletal outcome.

One of these models is the ecological model of musculoskeletal disorders in office work, presented by [29]. A modified version of this model, specifically targeting computer work has been proposed by Rempel in 2006.

Musculoskeletal discomforts are common occupational problems in healthcare workers whose job tasks involve repetitive motion and assumption of awkward positions. They are major causes of disability worldwide often resulting in job modification and outright resignation by many healthcare practitioners [32]. This work aimed to assess the prevalence and risk factors for musculoskeletal discomfort/pain prevalence of Work Related Musculoskeletal Discomforts (WRMD), risk factors to WRMD amongst computer users. Results revealed that the mean age of the respondents was $38.36 \pm 7.96$ years.

Results showed that $90.6 \%$ of computer users suffered symptoms of work related musculoskeletal complaints. Weight of the computer users and the duration of work session were reported as the possible risk factors for the development of musculoskeletal discomforts/pain [10]. This paper presents a web based musculoskeletal monitoring system with in-built predictive model for musculoskeletal pain among computer users.

\section{Literature Review}

\subsection{Musculoskeletal Pain in Nigeria}

[17] reported that in indigenous Africans, 650,000 people of estimated 965 million have computer use related problems. The burden of musculoskeletal pain in Nigeria is due to neglected working condition factors; mainly because of lack of orientation or under-reporting [2]. This is not peculiar to Nigeria but most parts of Africa.

In a study of musculoskeletal registry literature update from all over the world, only $1 \%$ of the literature emanated from Africa compared to $34 \%$ and $42 \%$ from Europe and Asia respectively. This is partly due to inaccurate population statistics which makes age specific incidence rates impossible or if available inaccurate. Other reasons are inadequate diagnostic facilities, limited access to care etc.

Inadequate technical manpower and infrastructure as well as quality of ergonomics data systems all contribute to inaccurate data on ergonomic burden. Annually, there are about 100,000 new musculoskeletal pain cases in Nigeria, this is estimated to increase to 500,000 in 2010 [2]. [41] estimates that incidence of musculoskeletal pain in Nigerian men and women by 2020 will be 807/1000 and $709 / 1000$. This is as a result of increase in the use of computers.

\subsection{Ergonomic Problem and Technology}

Human factors and ergonomics are concerned with the "fit" between the user, equipment and their environments. It takes account of the user's capabilities and limitations in seeking to ensure that tasks, functions, information and the environment suit each user. To assess the fit between a person and the used technology, human factors specialists or ergonomists consider the job (activity) being done and the 
Oluwole B. Olajide, Ikechukwu Nwosu and Samson Oluyemi Sogunro; Development of a Web-Based Musculoskeletal Pain Management Information System, Transactions on Networks and Communications,

Volume 3 No. 6, December (2015); pp: 1-17

demands on the user; the equipment used (its size, shape, and how appropriate it is for the task), and the information used (how it is presented, accessed, and changed). Ergonomics draws on many disciplines in its study of humans and their environments, including anthropometry, biomechanics and basically the engineering field.

One of the most prevalent types of work-related injuries is musculoskeletal disorders. Work-related musculoskeletal disorders (WRMDs) result in persistent pain, loss of functional capacity and work disability, but their initial diagnosis is difficult because they are mainly based on complaints of pain and other symptoms. Every year 1.8 million U.S. workers experience WRMDs and nearly 600,000 of the injuries are serious enough to cause workers to miss work.

Certain jobs or work conditions cause a higher rate worker complaints of undue strain, localized fatigue, discomfort, or pain that does not go away after overnight rest. These types of jobs are often those involving activities such as repetitive and forceful exertions; frequent, heavy, or overhead lifts; awkward work positions; or use of vibrating equipment.

The Occupational Safety and Health Administration (OSHA) have found substantial evidence that ergonomics programs can cut workers' compensation costs, increase productivity and decrease employee turnover. Therefore, it is important to gather data to identify jobs or work conditions that are most problematic, using sources such as injury and illness logs, medical records, and job analyses.

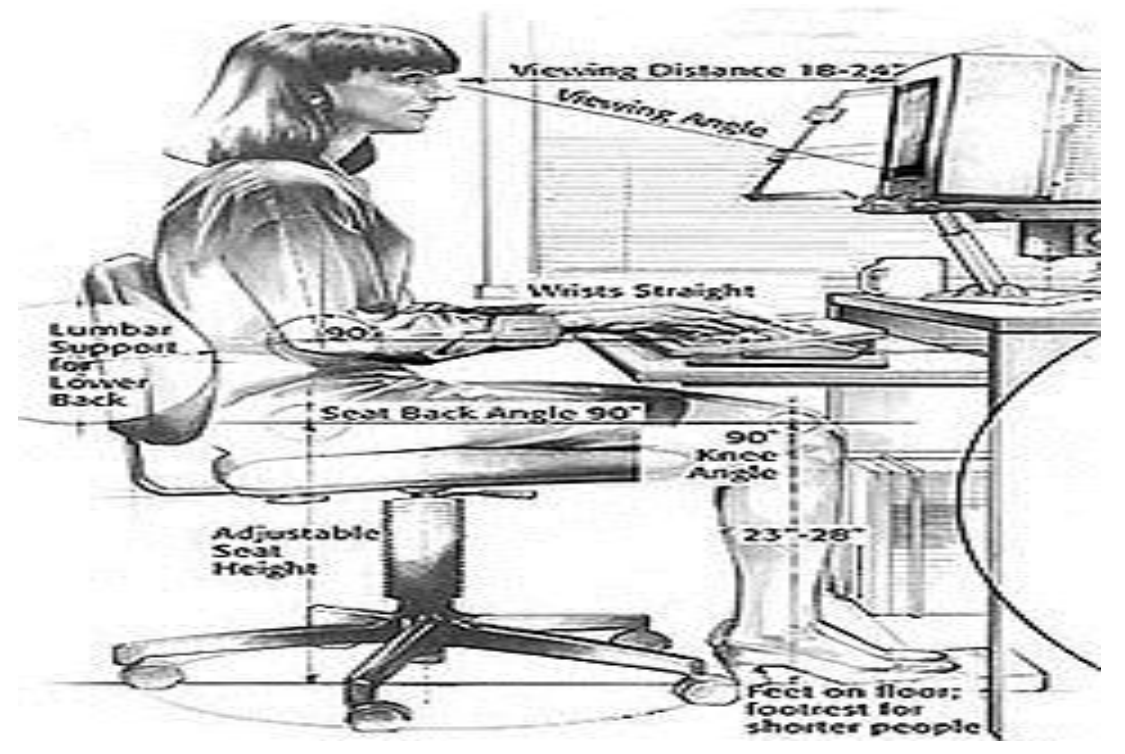

Figure 1: A Schematic View of Ergonomic use of a Computer

\subsection{Prediction of Musculoskeletal Pain}

The area of musculoskeletal pain prediction has been an area of study by many public health officials. It has become a way of easily mitigating the likelihood of the existence of the disease by determining the disease in its earlier stages [4]. 
Although the accurate prediction of musculoskeletal pain is not clear, oncologists have tried determining musculoskeletal pain likelihood via a number of data mining tools and bringing into view the risk factors that are responsible for the disease [31].

According to [16] prediction of musculoskeletal pain has provided estimates for future trends, useful to service planners, and highlights for tobacco control, to reduce numbers of musculoskeletal pain in Northern Ireland. The use of regression models proved to be the most practical means by which relatively short-term future patterns of musculoskeletal pain mortality can be estimated.

[22] stated also that genetic algorithm is a useful search procedure that searches from one population of points to another; thus directing the search to the beast solution so far rendering it as a global solution to non-linear functions.

According to [17] the genetic algorithm was used by Dr. Wolberg of the University of Wisconsin, Madison in correctly diagnosing pain as being either benign or malignant based on data from automated microscopic examination of cells collected by needle aspiration.

Musculoskeletal pain can affect the body's muscles, joints, tendons, ligaments and nerves. Most workrelated musculoskeletal pain develops over time and is caused either by the work itself or by the employees' working environment. MSD's can also occur in the patient's life outside work either through sport - tennis (elbow); music - guitar playing or a hobby - on-line tracing of a family tree.

These external work events can be exacerbated by their daily profession. They can also result from fractures sustained in an accident. Typically, musculoskeletal pains affect the back, neck, shoulders and upper limbs; less often they affect the lower limbs.

Health problems range from discomfort, minor aches and pains, to more serious medical conditions requiring time of musculoskeletal pain are a priority for the EU in its Community strategy. Reducing the musculoskeletal load of work is part of the 'Lisbon objective', which aims to create 'quality jobs' by:

- Enabling workers to stay in employment; and

- Ensuring that work and workplaces are suitable for a diverse population.

In an attempt to overcome limitations inherent in conventional computer-aided diagnosis, investigators have created programs that simulate expert human reasoning [35]. Hopes that such a strategy would lead to clinically useful programs have not been fulfilled, but many of the problems impeding creation of effective artificial intelligence programs have been solved.

Strategies have been developed to limit the number of hypotheses that a program must consider and to incorporate pathophysiologic reasoning. The latter innovation permits a program to analyse cases in which one disorder influences the presentation of another.

Prototypes embodying such reasoning can explain their conclusions in medical terms that can be reviewed by the user. Despite these advances, further major research and developmental efforts will be necessary before expert performance by the computer becomes a reality [3]. The steady expansion of medical knowledge has made it more difficult for the physician to remain a part of medicine outside a narrow field.

Consultation with a specialist is a solution when the clinical problem lies beyond the physician's competence, but frequently expert opinion is either unavailable or not available in a timely fashion. Attempts have been made to develop computer programs that can serve as consultants. 
Oluwole B. Olajide, Ikechukwu Nwosu and Samson Oluyemi Sogunro; Development of a Web-Based Musculoskeletal Pain Management Information System, Transactions on Networks and Communications, Volume 3 No. 6, December (2015); pp: 1-17

By the early 1970s it became clear that conventional tools such as flow charts, pattern matching and Bayes' theorem were unable to deal with most complex clinical problems. Investigators then began to study the expert physician to obtain detailed insights into the basic nature of clinical problem solving.

The results derived from such studies have subsequently formed the basis for computational models of the cognitive phenomena, and these models have further been converted into so-called artificial intelligence programs [42].

Many of the early efforts to apply artificial intelligence methods to real problems, including medical reasoning; have primarily used rule-based systems. Such programs are typically easy to create, because their knowledge is catalogued in the form of "if ... then..." rules used in chains of deduction to reach a conclusion. In many relatively well-constrained domains rule-based programs have begun to show skilled behaviour [31].

This is true in several narrow domains of medicine as well, but most serious clinical problems are so broad and complex that straightforward attempts to chain together larger sets of rules encounter major difficulties. Problems arise principally from the fact that rule-based programs do not embody a model of disease or clinical reasoning. In the absence of such models, the addition of new rules leads to unanticipated interactions between rules and thus to serious degradation of program performance.

Given the difficulties encountered with rule-based systems, more recent efforts to use artificial intelligence in medicine have focused on programs organized around models of disease. Efforts to develop such programs have led to substantial progress in our understanding of clinical expertise, in the translation of such expertise into cognitive models, and in the conversion of various models into promising experimental programs.

Of equal importance, these programs have been steadily improved through the correction of flaws shown by confronting them with various clinical problems. We will focus on how improved representation of clinical knowledge and sophisticated problem-solving strategies has advanced the field of artificial intelligence in medicine.

Our purpose is to provide an overview of artificial intelligence in medicine to the physician who has had little contact with computer science. We will not concentrate on individual programs; rather, we will draw on the key insights of such programs to create a coherent picture of artificial intelligence in medicine and the promising directions in which the field is moving.

We will therefore describe the behaviour not of a single existing program but the approach taken by one or another of the many programs to which we refer. It remains an important challenge to combine successfully the best characteristics of these programs to build effective computer-based medical expert systems. Several collections of papers provide detailed descriptions of the programs on which our analysis is based. Any program designed to serve as a consultant to the physician must contain certain basic features. It must have a store of medical knowledge expressed as descriptions of possible diseases. Depending on the breadth of the clinical domain, the number of hypotheses in the database can range from a few to many thousands.

In the simplest conceivable representation of such knowledge, each disease hypothesis identifies all of the features that can occur in the particular disorder. In addition, the program must be able to match 
what is known about the patient with its store of information. Even the most sophisticated programs typically depend on this basic strategy [42].

The simplest version of such programs operates in the following fashion when presented with the chief complaint and when later given additional facts.

- For each possible disease (diagnosis) determine whether the given findings are to be expected.

- Score each disease (diagnosis) by counting the number of given findings that would have been expected.

- Rank-order the possible diseases (diagnoses) according to their scores.

- The power of such a simple program can be greatly enhanced through the use of a mechanism that poses questions designed to elicit useful information. Take, for example, an expansion of the basic program by the following strategy:

- Select the highest-ranking hypothesis and ask whether one of the features of that disease, not yet considered, is present or absent.

- If inquiry has been made about all possible features of the highest-ranked hypothesis, ask about the features of the next best hypothesis.

- If a new finding is offered, begin again with step; otherwise, print out the rank-ordered diagnoses and their respective supportive findings and stop.

Steps 1 through 3 contain a primitive evaluation of the available information, and steps 4 through 6 contain an equally simple information-gathering strategy that determines what information to seek next. But such a program fails to capture many of the techniques responsible for expert performance. For example, the ranking process does not take into account how frequently particular features occur in a given disease.

The program, furthermore, has no knowledge of pathophysiology and is not able to take stock of the severity of an illness. The most serious problem is that each new finding sets into motion a search process tantamount to considering all disease states appearing in a textbook of medicine. Even for a high-speed computer this is not a practical diagnostic strategy and for this reason research has turned to the study of how experts perform.

The physician's ability to sharply limit the number of hypotheses under active consideration at any one time is a key element in expert performance [28]. Computer programs that use the strategies of experts can accomplish this same goal and devote the bulk of their computational resources to the sophisticated evaluation of a small number of hypotheses.

Controlling the proliferation of hypotheses is only the first step in creating effective artificial intelligence programs [26]. To deal with the circumstance in which one disease influences the clinical presentation of another, the program must also have the capacity to reason from cause to effect. Moreover, the required pathophysiologic knowledge must be organized in a hierarchical fashion so that the information becomes more detailed as one progress to deeper levels of the knowledge base.

Quantitative information, or rough qualitative estimates, must also be added to the causal links if the program is to separate the contribution of each of several disorders to a complex clinical picture [42]. 
Oluwole B. Olajide, Ikechukwu Nwosu and Samson Oluyemi Sogunro; Development of a Web-Based Musculoskeletal Pain Management Information System, Transactions on Networks and Communications,

Volume 3 No. 6, December (2015); pp: 1-17

The cognitive models that embody these principles provide the basis for computer programs that use the chief complaint and other available information to reduce the range of diagnostic possibilities. The narrowing process can be viewed as passive in that the program makes all possible progress without requesting further facts.

The passive phase completed, the program moves to an active mode of posing questions to the physician. This process is interactive with each new fact stimulating additional analysis that further reduces the number of diagnostic possibilities. In the following discussion, attention will be directed primarily to the passive narrowing process because this strategy plays a central role in clinical problem solving and because more is known about this process than about the active collection of new information [27].

\subsection{Related Work}

Various numbers of researches exists concerning musculoskeletal pain prediction although with varying factors and data mining methodology applied. According to [37], in the development of a musculoskeletal pain prediction model incorporating familial and personal risk factors he was able to determine the risk of the likelihood of the disease; although using only a limited number of risk factors while excluding occupational, environmental, social and dietary factors.

[7] performed a network-based survival analysis on two musculoskeletal pain datasets with the intention of determining how long a after an operation may the disease recur. [8] also performed a research on the determination of the positive association between the waist-hip ratio and the likelihood of musculoskeletal pain risk in urbanized Nigerian, although limited only to waist-hip ratio as a risk factor.

\section{Methods}

\subsection{Use Case Diagrams}

Use Cases are a requirements discovery technique first introduced in the object method. In its simplest form, a use case identifies the actors (in this case; the end-users and the administrators) involved in an interaction and the names and the types of the interaction. The use case diagram in Figure 2 describes all the actors and the interactions, which are possible by either users of the system.

The function of each use cases are described as follows:

i. Enter Personal Data: Each patient is prompted to register and login into the system to provide their personal data which consists of Name, Sex, age, ethnicity, occupation and city of residence;

ii. Enter Medical Data: Each patient is prompted after filing in their personal data to add their medical data which consists of information about the modifiable and non-modifiable risk factors;

iii. Determine Musculoskeletal Pain Status: Each patient is then prompted to submit the information which is used by the system in determining the status of the patient which can either be none, likely, benign or malignant;

iv. Perform Prediction Analysis: the doctor can perform the required predictive analysis by using the information available in the database - provided by the patients; and

v. Generate Report: after performing the required prediction analysis, the doctor can view the results via a report generated after analysis. 


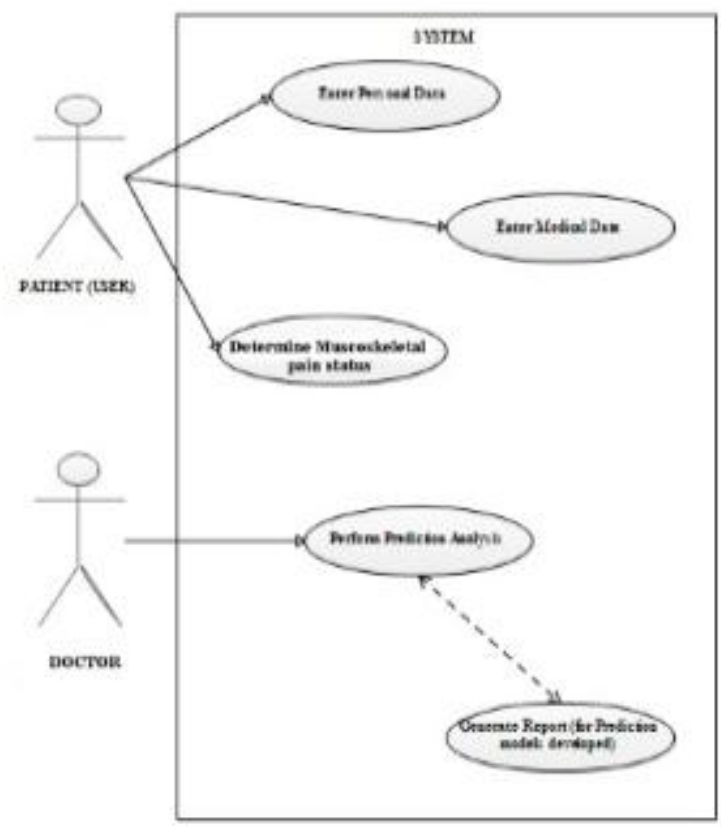

Figure 2: Use-Case diagram of user interaction with the system

\subsection{System Architecture}

This is the assessment, description or explanation of a system based on careful consideration or investigation of its operation. It is also described as the detailed explanation of a system to understand it better and draw conclusions from it. This is done by considering input, manipulating it and getting the desired output. Inputs for the software are the information (personal and medical information) that will be entered by the user of the software system.

The patient enters the personal data which includes the name, age, location, sex and previous medical records and automatically becomes a user. This goes into the system and is stored in the database of the musculoskeletal pain management system.

The system can be assessed by the patient and the doctor while the data given by the user is processed by the predictive system. Both the personal data and the medical data are stored in the musculoskeletal pain management systems' storage device which is also the database. After the prediction is done, the result is given as output.

The software was not meant to replace the specialist or doctor, yet it was developed to assist general practitioner and specialist in diagnosing and predicting patient's condition from certain rules or "experience". Patient with high-risk factors or symptoms or predicted to be highly effected with certain diseases or illness, could be short listed to see the specialist for further treatment. Employing the technology especially Artificial Intelligence (AI) techniques in medical applications could reduce the cost, time, human expertise and medical error. 
Oluwole B. Olajide, Ikechukwu Nwosu and Samson Oluyemi Sogunro; Development of a Web-Based Musculoskeletal Pain Management Information System, Transactions on Networks and Communications,

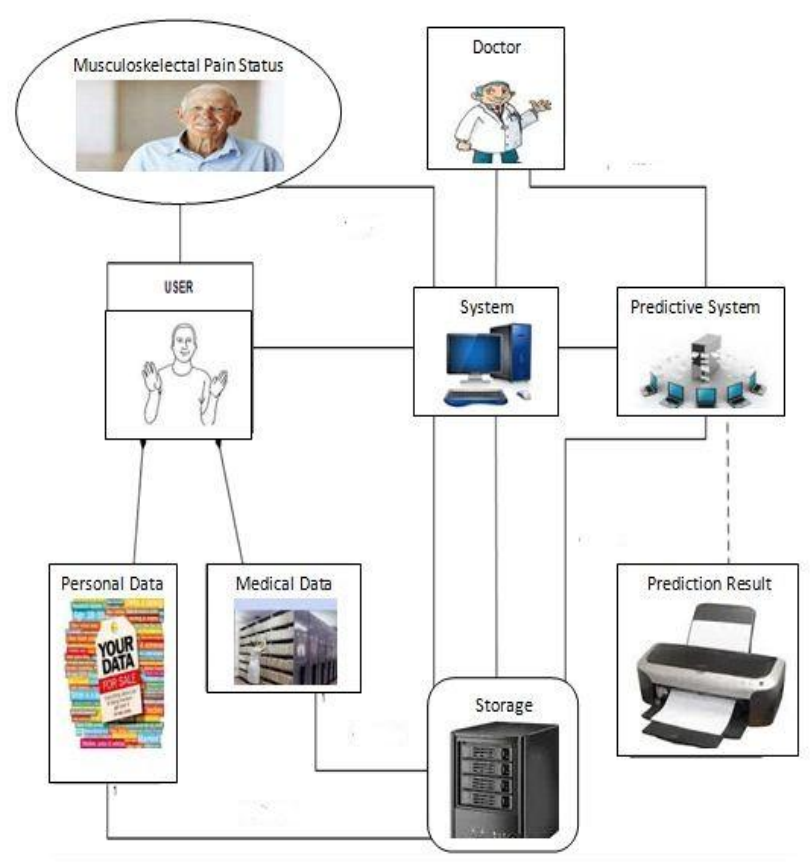

Figure 3: System Architecture of Musculoskeletal Pain Management Information System

\section{The Prototype}

\subsection{Implementation}

During implementation, the user interface of the software was implemented using the Netbeans 7.1 IDE (Integrated Development Environment), the predictive models are applied via the weka.jar file which is stored as a library whose methods are called and manipulated by the GUI. The data which is used in storing data and manipulating the predictive models was stored in .arff file format.

They are developed to facilitate the users computing environment. These interfaces were mainly implemented using Java programming language.

This user interface acts as the access point into the system for patients, doctors and administrators. Users are required to select their respective identification; patients are to select user while the doctor selects the administrator button.

\subsubsection{Welcoming the User}

The moment the application is being run; the system prompts the user to log in either as a patient (Figure 4 ), or as a doctor. For a patient user who wants to use the system, he may log in by selecting patient from the radio button as shown in the figure above. After log in, the user is prompted to fill in his/her personal and medical information.

\subsubsection{Patient Medical Information}

After every user is granted access to the system, the user is prompted to provide their personal information (Figure 4) and their medical information which consists of the modifiable and non-modifiable risk factors (Figure 5). The information provided by the user is populated into the database of the system; 
and is also retrieved by the system in determine the musculoskeletal pain status of the user and in performing predictive analysis by the doctor.

\subsubsection{Musculoskeletal Pain Status Report}

After the user provides his/her personal and medical information, the system then performs the required analysis needed in order to determine the musculoskeletal pain status of the patient by printing the results (see Figure 6) and also by providing recommendations to the patient as advice towards mitigating likelihood. But, the recommendations are made only to the non-modifiable risk factors.

\subsubsection{Doctor's Activity}

After a number of determinations were made by the detection system, the stored data was prepared for predictive analysis. After the doctor logs into the system, the data provided by the user can further perform either of two (3) predictive models on the patient data: Bayes' naïve, J48-trees multi-layer perception classifications (see Figure 5). The results of the three predictive models were compared and decisions made depending on the doctor's discretion.

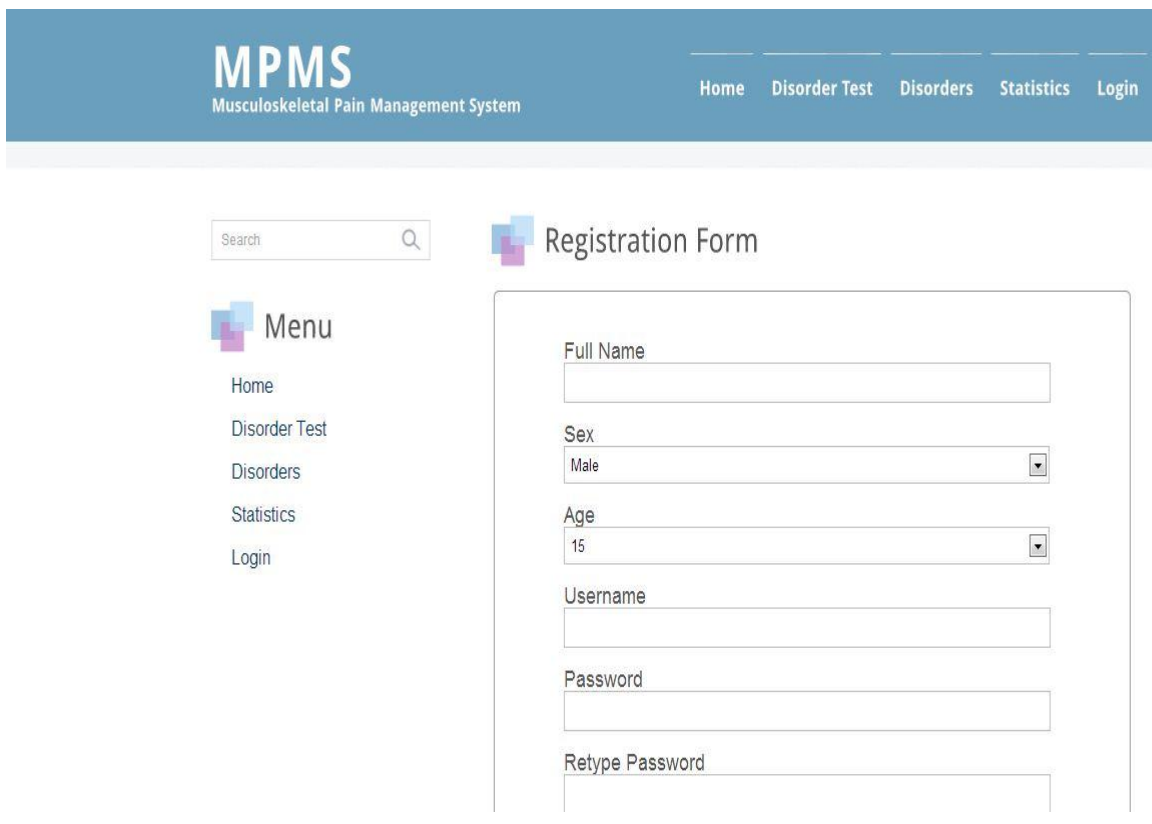

Figure 4: User Personal Information Window

\subsection{Welcome Page}

The moment the application is being run; the system prompts the user to log in either as a patient (Figure 4), or as a doctor. For a patient user who wants to use the system, he may log in by selecting patient from the radio button as shown in the figure above. After log in, the user is prompted to fill in his/her personal and medical information. This includes the full name, the sex, age, previous medical record, and the user registering the password twice for confirmation. 
Oluwole B. Olajide, Ikechukwu Nwosu and Samson Oluyemi Sogunro; Development of a Web-Based Musculoskeletal Pain Management Information System, Transactions on Networks and Communications,

Volume 3 No. 6, December (2015); pp: 1-17

\section{MPMS}

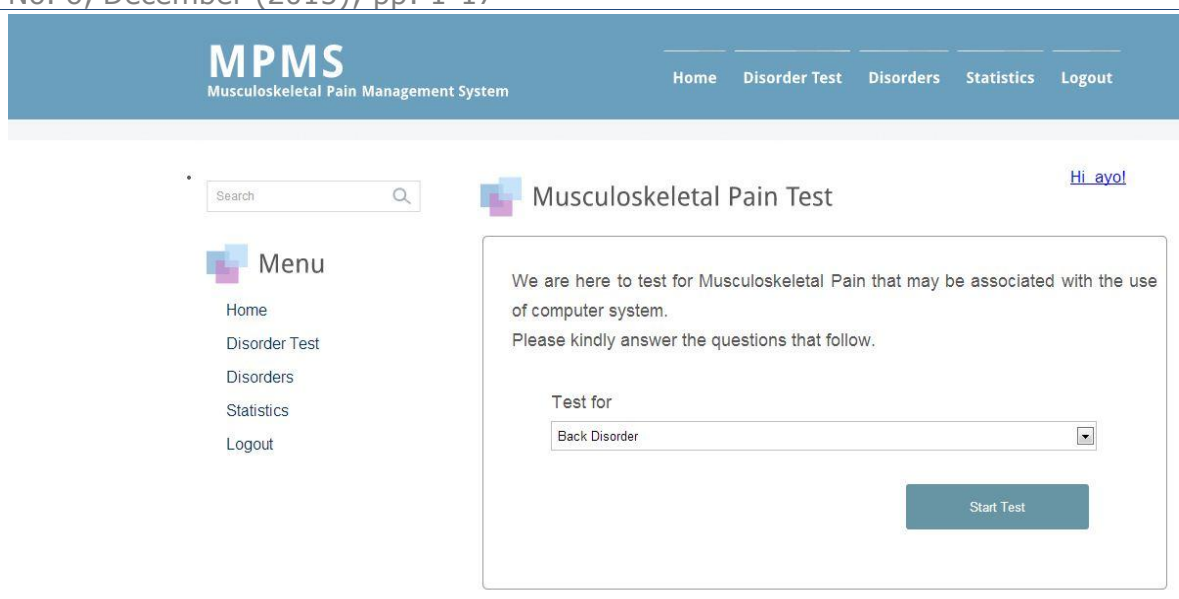

Figure 5: Medical Information Window

After every user is granted access to the system, the user is prompted to provide their personal information (Figure 4) and their medical information which consists of the modifiable and non-modifiable risk factors (Figure 5). The information provided by the user is populated into the database of the system; and is also retrieved by the system in determine the musculoskeletal pain status of the user and in performing predictive analysis by the doctor.

The user then answers a series of questions relating to the musculoskeletal disorder and awaits the result.

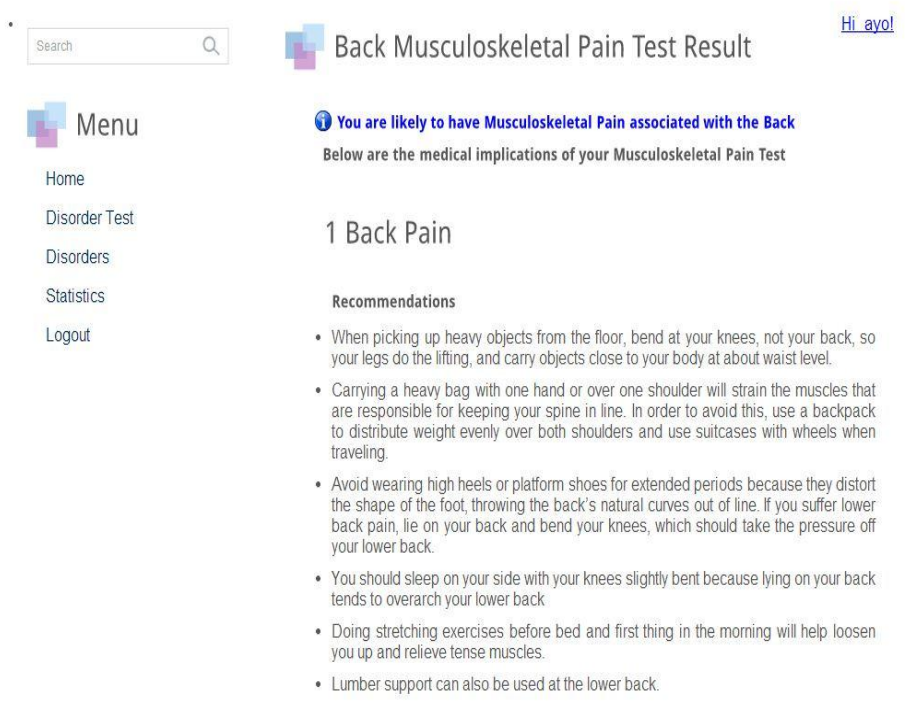

Figure 6: The Musculoskeletal Pain Status Report Window

After the user provides his/her personal and medical information, the system then performs the required analysis needed in order to determine the musculoskeletal pain status of the patient by printing the results (see Figure 6) and also by providing recommendations to the patient as advice towards mitigating likelihood. But, the recommendations are made only to the non-modifiable risk factors. Recommendations are also given to the user about musculoskeletal pain treatment and best practices. 


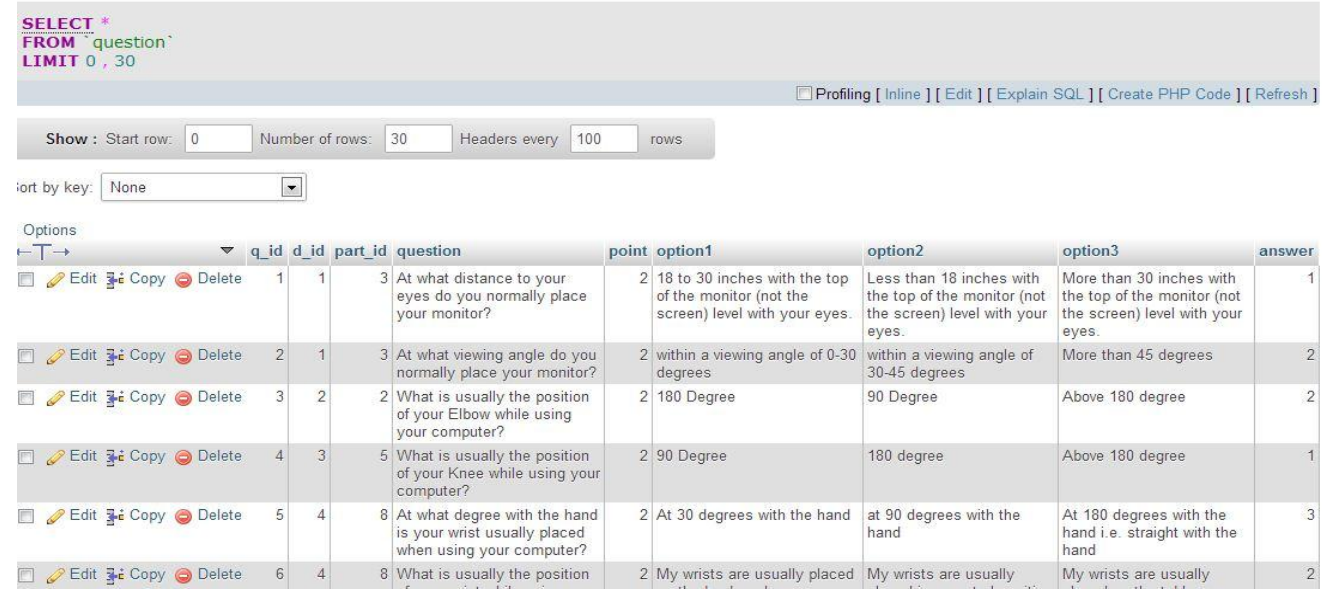

Figure 7: Questionnaire Data

\section{Conclusion}

The musculoskeletal pain detection and prediction software system was discovered to be of good use to the public health sector; especially with the interactive user-interface it has and with its ability to provide effective detection of the disease just by identifying the risk factors associated with the disease. It is also very effective at predicting the likelihood of the disease in the lives of individuals by simply analyzing available and known cases using effective predictive models.

Musculoskeletal pain is indeed a major threat to the general populace of our nation, Nigeria; and it is imperative that means via which the progress and distribution of musculoskeletal pain must be developed and identified.

There is need for the Nigerian Public Health sector to look into ways via which this killer disease can be mitigated if not cured before it becomes a living menace in the lives of our mothers. Women are the procreators of life and the determining factor of human existence, if there is increasing growth in the number of deaths due to this disease then there is no hope for the future of the Nigerian child and the nation at large.

\section{REFERENCES}

[1] Andersen JH, Haahr JP, Frost P: Risk factors for more severe regional musculoskeletal symptoms: a two-year prospective study of a general working population. Arthritis Rheum 2007, 56(4):1355-1364. [http://www.av.se/dokument/statistik/officiell_stat/ARBORS2010.pdf].

[2] Arvidsson I, Axmon A, Skerfving S: Follow-up study of musculoskeletal disorders 20 months after the introduction of a mouse-based computer system. Scand J Work Environ Health 2008, 34(5): p. 374-380.

[3] Balogh I, Orbaek P, Ohlsson K, Nordander C, Unge J, Winkel J, Hansson GA: Self-assessed and directly measured occupational physical activitiesinfluenceof musculoskeletal complaints, age and gender. Appl Ergon 2004, 35(1): p. 49-56. 
Oluwole B. Olajide, Ikechukwu Nwosu and Samson Oluyemi Sogunro; Development of a Web-Based Musculoskeletal Pain Management Information System, Transactions on Networks and Communications,

Volume 3 No. 6, December (2015); pp: 1-17

[4] Bongers PM, ljmker S, van den Heuvel S, Blatter BM: Epidemiology of work related neck and upper limb problems: psychosocial and personal risk factors (part I) and effective interventions from a bio behavioural perspective (part II). J Occup Rehabil 2006, 16(3): p. 279-302.

[5] Bostrom M, Dellve L, Thomee S, Hagberg M: Risk factors for generally reduced productivity-a prospective cohort study of young adults with neck or upper-extremity musculoskeletal symptoms. Scand J Work Environ Health 2008, 34(2): p. 120-132

[6] Borg G: Psychophysical scaling with applications in physical work and the perception of exertion. Scand J Work Environ Health 1990, 16(Suppl 1): p. 55-58.

[7] Chih-lin A, Gustafsson M, Hansson GA: Effects of prismatic glasses including optometric correction on head and neck kinematics, perceived exertion and comfort during dental work in the oral cavity-a randomised controlled intervention. Appl Ergon 2012, 43(1): p. 246-253.

[8] Clement $\mathrm{M}$ : Risk of musculoskeletal disorders among females and males in repetitive/constrained work. Ergonomics 2009, 52(10): p. 1226-1239.

[9] Deitel M, Deitel C (1999a). Data Mining for Medical Database. Proceedings of the First National Conference on Artificial Intelligence Application in Industry. Kuala Lumpur, pp. 72-79.

[10] European Foundation for the improvment of living and working conditions. [http://www.eurofound.europa.eu/pubdocs/2006/98/en/2/ ef0698en.pdf].

[11] Ergonomic checklist for computer work. 1997 [http://www.sahlgrenska. se/upload/SU/omrade_6/Arbets-\%20och\%20Miljömedicin/AMM/fhvmetodik/checklista.pdf].

[12] Feuerstein M: Functional assessment for persons with musculoskeletal pain and impairment. J Occup Rehabil 2004, 14(3): p. 163-164.

[13] Feuerstein M, Nicholas RA: Development of a short form of the Workstyle measure. Occup Med 2006, 56(2): p. 94-99.

[14] Hajek k.I, Zelic, I., Lavrac, N., Najdenov, P., Rener-Primec, Z. (1999). Impact of machine Learning of the Diagnosis and Prognosis of First Cerebral Paroxysm. Machine Learning and Applications: Machine Learning in Medical Applications. Chania, Greece, p. 24-26.

[15] Hagberg M, Vilhemsson R, Tornqvist EW, Toomingas A: Incidence of selfreported reduced productivity owing to musculoskeletal symptoms: association with workplace and individual factors among computer users. Ergonomics 2007, 50(11): p. 1820-1834.

[16] Hanvold TN, Veiersted KB, Waersted M: A prospective study of neck, shoulder, and upper back pain among technical school students entering working life. J Adolesc Health 2010, 46(5): p. 488494. 
[17] Hansson GA, Balogh I, Bystrom JU, Ohlsson K, Nordander C, Asterland P, Sjolander S, Rylander L, Winkel J, Skerfving S: Questionnaire versus direct technical measurements in assessing postures and movements of the head, upper back, arms and hands. Scand J Work Environ Health 2001, 27(1): p. 30-40.

[18] Harrington CB, Siddiqui A, Feuerstein M: Workstyle as a predictor of pain and restricted work associated with upper extremity disorders: a prospective study. J Hand Surg Am 2009, 34(4)

[19] Juul-Kristensen B, Sogaard K, Stroyer J, Jensen C: Computer users' risk factors for developing shoulder, elbow and back symptoms. Scand J Work Environ Health 2004, 30(5): p. 390-398.

[20] Juul-Kristensen B, Jensen C: Self-reported workplace related ergonomic conditions as prognostic factors for musculoskeletal symptoms: the "BIT"follow up study on office workers. Occup Environ Med 2005, 62(3): p. 188-194.

[21] Karlqvist LK, Bernmark E, Ekenvall L, Hagberg M, Isaksson A, Rostö T: Computer mouse position as a determinant of posture, muscular load and perceived exertion. Scand J Work Environ Health 1998, 24(1): p. 62-73.

[22] Lindegård A, Wahlström J, Hagberg M, Hansson G-Å, Jonsson P, Wigaeus Tornqvist E: The impact of working technique on physical loads - an exposure profile among newspaper editors. Ergonomics 2003, 46(6): p. 598-615.

[23] Lindegård Andersson A: Working technique during computer work. Arbeteoch Hälsa 2007, 41:1

[24] Lindegård et al. BMC Musculoskeletal Disorders 2012, 13:38 http://www.biomedcentral.com/1471-2474/13/38

[25] Lindegård A, Gustafsson M, Hansson GA: Effects of prismatic glasses including optometric correction on head and neck kinematics, perceived exertion and comfort during dental work in the oral cavity-a randomised controlled intervention. Appl Ergon 2012, 43(1): p. 246-253.

[26] Nicholas RA, Feuerstein M, Suchday S: Workstyle and upper-extremity symptoms: a biobehavioral perspective. J Occup Environ Med 2005,47(4): p. 352-361.

[27] Nordander C, Ohlsson K, Akesson I, Arvidsson I, Balogh I, Hansson GA, Stromberg U, Rittner R, Skerfving S: Risk of musculoskeletal disorders among females and males in repetitive/constrained work. Ergonomics 2009, 52(10): p. 1226-1239.

[28] Norman K, Floderus B, Hagman M, Toomingas A, Tornqvist EW: Musculoskeletal symptoms in relation to work exposures at call centre companies in Sweden. Work 2008, 30(2): p. 201-214.

[29] Rempel D, Barr A, Brafman D, Young E: The effect of six keyboard designs on wrist and forearm postures. Appl Ergon 2007, 38(3): p. 293-298 
Oluwole B. Olajide, Ikechukwu Nwosu and Samson Oluyemi Sogunro; Development of a Web-Based Musculoskeletal Pain Management Information System, Transactions on Networks and Communications,

Volume 3 No. 6, December (2015); pp: 1-17

[30] Rempel DM, Krause N, Goldberg R, Benner D, Hudes M, Goldner GU: A randomised controlled trial evaluating the effects of two workstation interventions on upper body pain and incident musculoskeletal disorders among computer operators. Occup Environ Med 2006, 63(5): p. 300306.

[31] Rothman KJ, Greenland S, Lash TL: Modern epidemiology Philadelphia: Lippincott Williams \& Wilkins; 2008.

[32] Roquelaure $\mathrm{Y}, \mathrm{Ha}$ C, Leclerc A, Touranchet A, Sauteron M, Melchior M,Imbernon E, Goldberg M: Epidemiologic surveillance of upper-extremity musculoskeletal disorders in the working population. Arthritis Rheum 2006, 55(5): p. 765-778.

[33] Sauter SL, Swanson NG: An ecological model of musculoskeletal disorders in office work. In Beyond biomechanics: Psychosocial aspects of musculoskeletal disorders in office work Edited by: Moon SD, Sauter SL 1996: p. 3-21.

[34] Sillanpää J, Huikko S, Nyberg M, Kivi P, Laippala P, Uitti J: Effect of work with visual display units on musculo-skeletal disorders in the office environment. Occup Med 2003, 53(7): p. 443-451.

[35] Stock SR, Fernandes R, Delisle A, Vezina N: Reproducibility and validity of workers' self-reports of physical work demands. Scand J Work Environ Health 2005, 31(6): p. 409-437.

[36] Tornqvist EW, Hagberg M, Hagman M, Risberg EH, Toomingas A: The influence of working conditions and individual factors on the incidence of neck and upper limb symptoms among professional computer users. Int Arch Occup Environ Health 2009, 82(6): p. 689-702.

[37] Tyrer KJ, Greenland S, Lash TL: Modern epidemiology Philadelphia: Lippincott Williams \& Wilkins; 2008. Veiersted KB, Westgaard RH: Development of trapezius myalgia among female workers performing light manual work. Scand J Work Environ Health 1993, 19(4): p. 277-283.

[38] Wahlstrom J, Lindegard A, Ahlborg G Jr, Ekman A, Hagberg M: Perceived muscular tension, emotional stress, psychological demands and physical load during VDU work. Int Arch Occup Environ Health 2003, 76(8): p. 584-590.

[39] Wahlstrom J: Ergonomics, musculoskeletal disorders and computer work. Occupational Medicine 2005, 55(3): p. 168-176.

[40] Wahlstrom J, Hagberg M, Toomingas A, Wigaeus Tornqvist E: Perceived muscular tension, job strain, physical exposure, and associations with neck pain among VDU users; a prospective cohort study. Occup Environ Med 2004, 61(6): p. 523-528.

[41] World Health Organization. World Cancer Report 2008. Lyon: International Agency for Research on Cancer;2008 
[42] Walker-Bone K, Palmer KT, Reading I, Coggon D, Cooper C: Prevalence and impact of musculoskeletal disorders of the upper limb in the general population. Arthritis Rheum 2004, 51(4): p. 642-651

[43] Zelic, I., Lavrac, N., Najdenov, P., Rener-Primec, Z. (1999). Impact of machine Learning of the Diagnosis and Prognosis of First Cerebral Paroxysm. Machine Learning and Applications: Machine Learning in Medical Applications. Chania, Greece: p. 24-26. 